\title{
Influence of Different Types of Emulsifiers on Properties of Emulsified Asphalt Binder and Its Evaporation Residue by Molecular Dynamics Simulation
}

\author{
Ying-feng $W u \mathbb{D}^{1}$ and $X i n Q u \mathbb{D}^{2}$ \\ ${ }^{1}$ Zhejiang Institute of Communications, Hangzhou, China \\ ${ }^{2}$ Key Laboratory of Road Structure and Material, Ministry of Communication, Chang'an University, Xi'an, China \\ Correspondence should be addressed to Ying-feng Wu; wuyingf_hz@hotmail.com
}

Received 2 September 2021; Accepted 29 November 2021; Published 9 December 2021

Academic Editor: Antonio Caggiano

Copyright (C) 2021 Ying-feng Wu and Xin Qu. This is an open access article distributed under the Creative Commons Attribution License, which permits unrestricted use, distribution, and reproduction in any medium, provided the original work is properly cited.

\begin{abstract}
There is an important role in the properties of emulsified asphalt binder and its evaporation residue about emulsifier, which has been confirmed by experiment and chemical tests. However, there is little research about the emulsifier at microperspective. Therefore, the influence of two kinds of emulsifiers, a typical cationic emulsifier (dodecyl benzene sulfonate) and a typical anionic emulsifier (dodecyl primary amine), on technical properties of emulsified asphalt binder and its evaporation residues such as store stability, workability, breaking behavior, and mechanical properties are investigated using a microapproach. Results show that there is an effective role in the storage stability, workability, and demulsification of emulsified asphalt binder about cationic emulsifier compared with anionic emulsifier. The anionic emulsifier makes the density of evaporation residue larger. However, the mechanical properties of anionic emulsified asphalt evaporation residue are conversely smaller compared with the cationic emulsified asphalt evaporation residue. The adhesion behavior results have confirmed that the anionic emulsified asphalt evaporation residue has a negative adhesion with aggregate due to its anion. The mechanism of the different emulsifiers on asphalt binders and their evaporation residue is explored at a microscale to help us to understand emulsified asphalt binder and its evaporation residue more in depth.
\end{abstract}

\section{Introduction}

Emulsified asphalt refers to an oil-in-water $(\mathrm{O} / \mathrm{W})$ emulsion formed by heating and melting asphalt and dispersing fine particles in a solution containing an emulsifier and water under mechanical agitation [1]. In other words, emulsified asphalt is a mixture of asphalt material with compositions of chemical composition, such as emulsifier and water. It is liquid state at room temperature, so it can be mixed with aggregate at room temperature to prepare the asphalt mixture, mixing paving; the real process does not need to consume energy and will not emit gas such as asphalt smoke. Emulsified asphalt saves energy by $40 \% \sim 50 \%$, improves construction conditions, reduces construction cost by $20 \% \sim 30 \%$, and can effectively reduce the excessive aging of asphalt caused by high-temperature heating and a large amount of volatilization of carcinogen benzoyl [2]. In addition, the application of emulsified asphalt in metal anticorrosion, desert sand fixation, slope stability, etc., has also been reported [3-5]. Therefore, in recent years, with the deterioration of environmental problems [6-8], emulsified asphalt has once again become the focus of research.

Emulsified asphalt is developed along with the development and application of surfactants for asphalt. In addition to the processing technology, the type, structure, and composition of the emulsifier determine the basic properties and application range of the emulsified asphalt for the determined matrix asphalt. According to the electrical properties of the emulsifier used, it is classified into three types, including cationic emulsified asphalt, anionic emulsified asphalt, and nonionic emulsified 
asphalt $[9,10]$. In the emulsified asphalt, the asphalt binder and water are mature and their natures are stable. Some previous research has confirmed that the properties of emulsifiers are crucial to the properties of emulsified asphalt. So, the emulsifier has been studied in this paper.

From the clay emulsified asphalt of the United States in 1914, a variety of anionic emulsified asphalt products were developed. There are many varieties of anionic emulsifiers, and the price is relatively low, but the anionic emulsified asphalt has poor adhesion to mineral materials, especially moist mineral materials and alkaline mineral materials. With the deepening of the understanding of surfactants and the development of colloidal chemistry and interfacial chemistry, the cationic emulsified asphalt that appeared in the 1960s effectively compensated for the shortage of anionic emulsified asphalt and improved the early strength of film formation. The performance is better under the conditions. In the 1960 s, France and the United States realized the commercialization of cationic asphalt emulsions. At the end of the 1970s, China began to study cationic asphalt emulsion and achieved a series of achievements in the processing technology of emulsion, emulsification equipment, and emulsion-testing standards and methods, which laid a good foundation for the promotion and application of emulsified asphalt.

From the structural point of view, the emulsifier is an amphiphilic molecule, which consists of a nonpolar hydrophobic group and a polar hydrophilic group. This structure causes the emulsifier to form a tightly aligned orientation on the surface of the solution, which changes the surface chemistry of the system. When the concentration of the emulsifier exceeds its critical micelle concentration (CMC), the surface tension is minimized, thereby having functions of emulsification, defoaming, dispersion, and so on. According to the hydrophilic and lipophilic balance value (HLB) of the emulsifier, the range of application can be preliminarily determined [11]. The asphalt emulsifier is between 10 and 18. Since the specific surface area of asphalt is large in the emulsion, the emulsifier concentration is much larger than that of the CMC to achieve the purpose of sufficient emulsification, and the amount of the emulsifier is generally controlled in the range of $0.13 \%$ to $3 \%$ (mass fraction) of the emulsion.

The influence of emulsifiers on the properties of emulsified asphalt binder and its evaporation residue has been researched comprehensively [1]. However, there are still some microissues that have not yet been clarified. So, the microscopic parameters of the emulsified asphalt binder are studied with molecular dynamics (MD) simulation, to understand the microscopic mechanism affecting the properties of the emulsified asphalt binder.

The influence of a typical cationic emulsifier (dodecyl benzene sulfonate) and a typical anionic emulsifier (dodecyl primary amine) are studied on the properties of the emulsified asphalt binder such as store stability, workability, and breaking behavior, as well as the mechanical properties and adhesion behavior of their evaporation residue.

\section{Model and Methodology}

2.1. The Molecular Dynamics Simulation. The influence of asphalt emulsifiers is studied with molecular dynamics simulation, which is a powerful tool to study asphalt binder $[4,5,12-14]$. Some applications of this technology in our previous studies were researched. The self-healing behavior of the asphalt binder is affected by different parameters [15], and the microproperties are affected by asphalt aging [16].

The structural characteristics of ionic liquids consisting of anions or cations often make them uniquely different from traditional asphalt binders. Well comprehending of the physicochemical properties of ionic liquids and the relationship between structure and physicochemical properties are the basis for the correct application of them to actual production. Many parameters of emulsified asphalt are directly related to their chemical stability and mechanical properties; therefore, the MD simulation research of the emulsified asphalt binder is necessary based on a microscopic viewpoint.

\subsection{Establishment of the Molecular Structure Model}

2.2.1. Asphalt Binder. Asphalt binders consist of millions of different components [17]. For the purpose of convenience of asphalt binder research, which was divided into three, four, or six fractions with similar properties, and then, the molecular structure has been created for each fraction $[18,19]$. Later, the 12-component asphalt model was first put forward by Li and Greenfield [3] to describe SHRP core asphalt binder AAA-1, and it has been popularized and applied in the research field [14, 16]. So, the structure of 12 molecules for the asphalt binder is created in this paper; the number of each structure and the verification process can be found in the work of Li and Greenfield [3].

2.2.2. Typical Emulsifier. A cationic emulsifier, like other types of emulsifiers, consists of a long-chain oleophilic group and a hydrophilic group, except that its hydrophilic group is a positively charged group, and its long-chain lipophilic group is usually composed of fatty acids or petroleum chemicals are derived. Theoretical studies and experiments have shown that the emulsifier oleophilic group is a linear alkane with a strong emulsification performance, and the emulsion tends to be stable with the increase of the emulsifier ketone-based carbon chain length grade saturation, so we initially designed the emulsification.

In this study, a typical cationic emulsifier (dodecyl benzene sulfonate) and a typical anionic emulsifier (dodecyl primary amine) are studied, which are shown in Figure 1. These two molecules were chosen because of their typical structure and have been studied in depth by scholars [20-22], so they can effectively characterize the characteristics of typical cationic and anionic emulsifiers.

2.2.3. Emulsified Asphalt Binder. According to the molecular structure models of the asphalt binder and the emulsifier, models of the emulsified asphalt binder should be created to investigate the influence of the emulsifier on the 


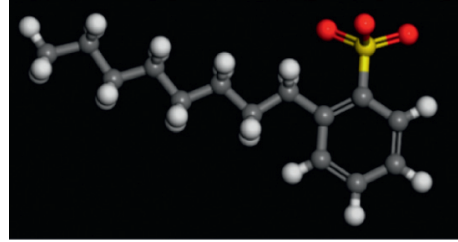

(a)

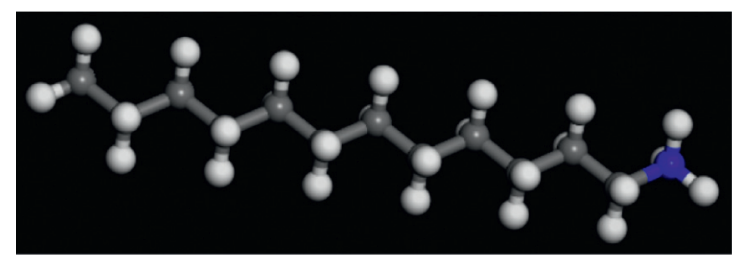

(b)

Figure 1: (a) Dodecyl benzene sulfonate. (b) Dodecyl primary amine.

emulsified asphalt binder. So, we put some molecular models of emulsifier and water into the asphalt binder model to create models of the emulsified asphalt binder; then, two kinds of the emulsified asphalt binder are created. In this paper, the solid content of the emulsified asphalt is assumed to be $60 \%$, and we put 1207 water molecules into the asphalt binder model, therefore, to create mixture of asphalt binder and water. Then, we put 3 dodecyl benzene sulfonate and 5 dodecyl primary amine into this mixture to create cationic and anionic emulsified asphalt binder, respectively.

2.2.4. Emulsified Asphalt Evaporation Residue. The forms of the emulsified asphalt binder are different because, after the pavement construction, the water is extruded out and volatilized from the emulsified asphalt binder; then, the emulsified asphalt evaporation residue works in the pavement. However, the emulsifier is still in the asphalt binder, so we take out the water molecules from the emulsified asphalt binder created above to build models of emulsified asphalt evaporation residue.

\section{Results and Discussion}

Currently, the emulsified asphalt binder is widely used in road engineering due to its construction convenience and environmental friendliness. However, its form changes during the usage: a lot of water are in the emulsified asphalt binder, so it is liquid before construction; while it will be semisolid after construction because the emulsified asphalt binder will be demulsified during the mixing with aggregate, and the evaporation residue of emulsion is similar as the asphalt binder. So, these different forms should be considered to investigate the influence of emulsifiers on the emulsified asphalt binder and its evaporation residue.

Therefore, the microproperties of emulsifiers, emulsified asphalt binder, and emulsified asphalt evaporation residue will be investigated in this paper. After the different models were created, molecular dynamics simulation was calculated with $100 \mathrm{ps}\left(1 \mathrm{ps}=10^{-12} \mathrm{~s}\right)$. In the particular $(\mathrm{NPT})$ state, which means the environment of the molecule is isothermal and isobaric, then the microproperties of models were obtained after the calculation.

3.1. Surface Tension of Emulsifier. The surface tension is a kind of basic property of the emulsifier, which can be obtained by the simulation directly. In the emulsified asphalt binder, the lower the surface tension of the cationic emulsifier, the easier the emulsification [23]. So, the surface tension of the two kinds of emulsifiers is calculated firstly. The results are shown in Figure 2.

It is seen that the surface tension of the cationic emulsifier is lower comparing with the anionic emulsifier. Hence, it is concluded that the cationic emulsifier is easier to mix with asphalt and water, i.e., it has a better effect to produce the emulsified asphalt binder.

3.2. Stability of the Emulsified Asphalt Binder. The emulsified asphalt binder is a kind of thermodynamic instability system, so the stability of the emulsified asphalt binder is analyzed with the classical Derjguin-Landau-Verwey-Overbeek (DLVO) theory. The theory concludes that the structural stability of emulsion depends on the interaction between particles in the emulsified asphalt binder [24]. The system is stable if the repulsive force is greater than the attractive force, otherwise, it is unstable $[25,26]$. The force between the colloidal particles is Van der Waals forces. The colloidal particles are aggregates of many molecules, so the interaction between them is the sum of the interaction between molecules.

The Van der Waals forces of the cationic emulsified asphalt, anionic emulsified asphalt, and asphalt binder are shown in Figure 3(a).

Figure 3(a) shows that the asphalt binder has the lowest Van der Waals force, indicating that the asphalt binder has the most stable colloidal structure. Meanwhile, the stability of the both emulsified asphalt binders is worse, which is in line with objective facts, i.e., the emulsified asphalt binder has the possibility of breaking. Compared with the two kinds of the emulsified asphalt binder, the cationic emulsified asphalt binder has a low Van der Waals force, indicating that repulsive force in the cationic emulsified asphalt binder is smaller; therefore, the stability of which is slightly superior to that of the anionic binder; it is consistent with the result of surface tension mentioned in the last section. It can be inferred that the cationic binder is also superior to anionic one in storage stability; this is the same as Tian's conclusion [27]. The storage stability is studied by the storage test; the results indicate the difference of softening point values between the bottom and top of the experimental sample. So, the larger the result value is, the more unstable the emulsified asphalt binder is.

3.3. Workability of the Emulsified Asphalt Binder. The workability of the emulsified binder is important for road construction because, when starting to mix with the 


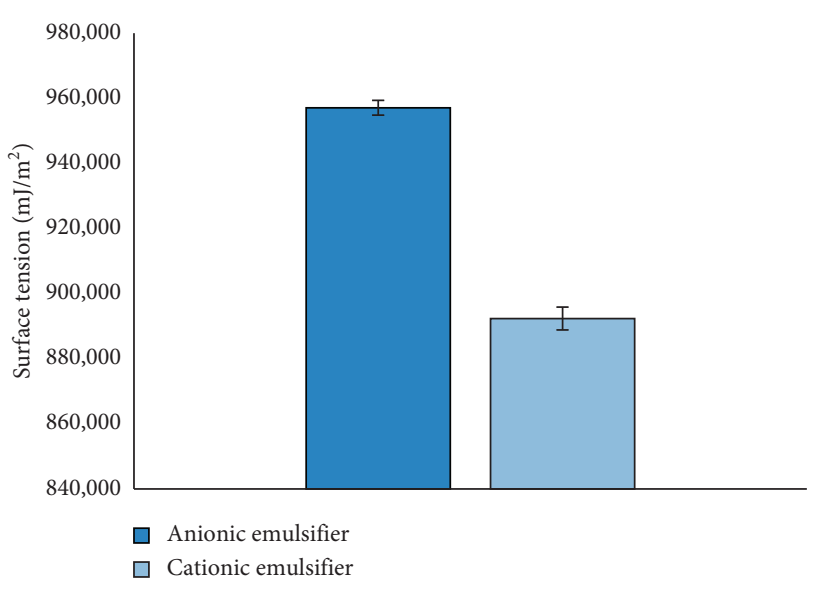

FIgURE 2: The surface tension results of the two kinds of the emulsifier.

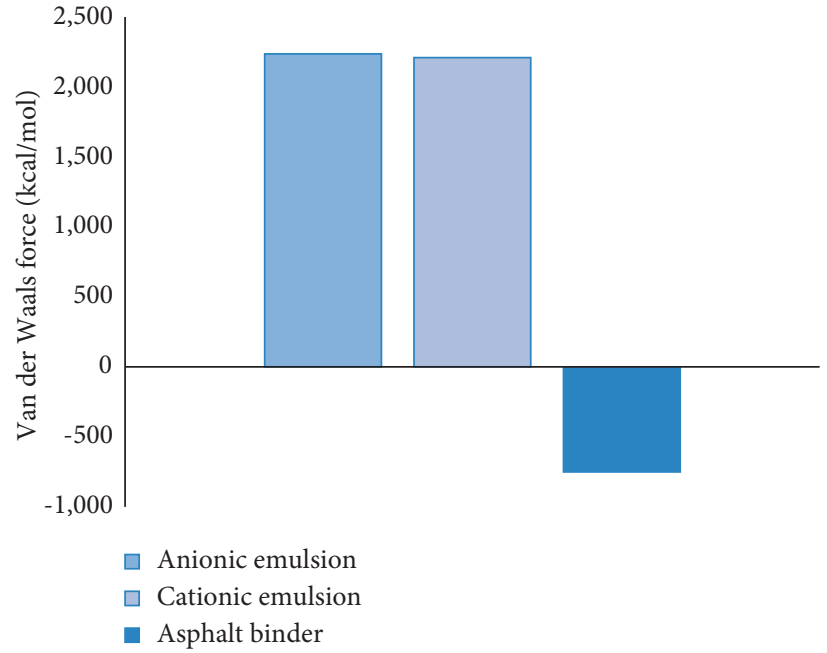

(a)

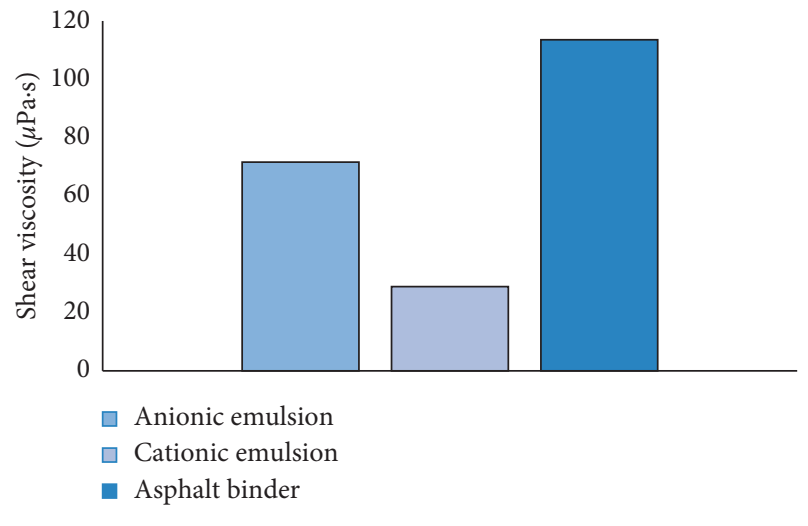

(b)

Figure 3: (a) The Van der Waals force of different kinds of samples. (b) The shear viscosity of different kinds of samples.

aggregate, it will have breaking behavior [27, 28]. Therefore, its viscosity should be as small as possible to make the mixing more uniform [29].

The viscosity of the emulsified asphalt binder is calculated using the MD simulation. Here, the shear viscosity is employed to investigate the workability because the shear viscosity is the main force characteristics during mixing; the shear viscosity is the main force characteristics during mixing if the shear viscosity is smaller, indicating the workability is better. The shear viscosity at $25^{\circ} \mathrm{C}$ of different samples is shown in Figure 3(b).

It shows that the shear viscosity of the binder is larger than the two kinds of the emulsified binder, while the cationic emulsified asphalt binder has the lowest shear viscosity. It means the cationic emulsified asphalt binder provides a lower mixing resistance, leading to better workability and road construction quality.
3.4. Breaking of the Emulsified Asphalt Binder. In the emulsified asphalt, the emulsifier lies between the asphalt binder and water and keeps stable due to chemical response. The chemical response will be broken during the emulsified asphalt breaking. Furthermore, the breaking process is curial for the emulsified asphalt mixture; it determines the wrap effect of the binder on aggregate, and it influences the mechanical properties of asphalt mixture significantly [30]. So, it should be understood more in depth.

To research the interaction response between emulsifier and asphalt binder/water, four interface models are created to investigate the interface energy; they are shown in Figure 4.

To evaluate the interface response, the interaction energy between the bituminous binder and the emulsifier is calculated based on equation (1), and the interaction energy between water and emulsifier is calculated by equation (2). 


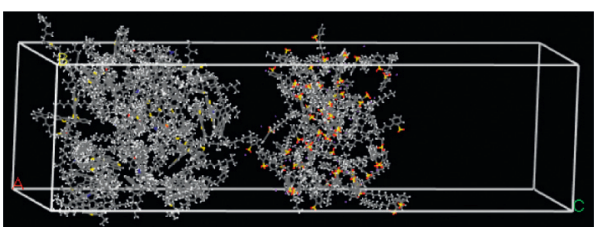

(a)

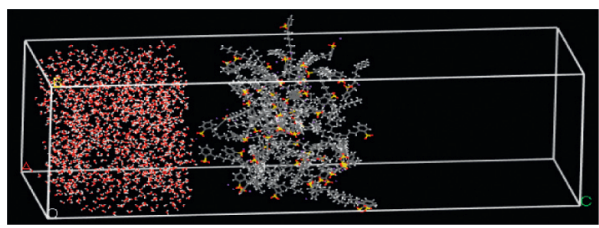

(c)

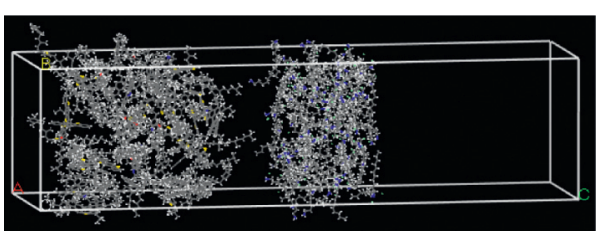

(b)

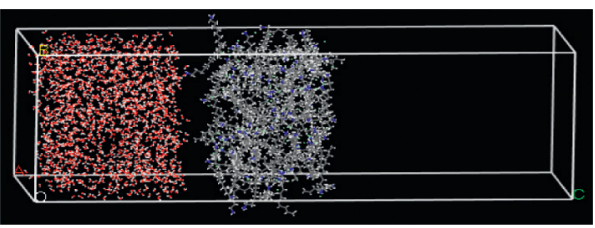

(d)

FiguRE 4: The interface between emulsifier and asphalt binder/water: (a) asphalt binder vs. cationic emulsifier; (b) asphalt binder vs. anionic emulsifier; (c) water vs. cationic emulsifier; (d) water vs. anionic emulsifier.

This method draws on some research on the adhesion between aggregate and bituminous binder. This approach was successfully used to calculate the adhesion work between aggregate and bituminous binder [31]:

$$
\begin{aligned}
& \Delta E_{\text {interface }}=E_{\text {total }}-\left(E_{\text {asphalt binder }}+E_{\text {emulsifier }}\right), \\
& \Delta E_{\text {interface }}=E_{\text {total }}-\left(E_{\text {water }}+E_{\text {emulsifier }}\right) .
\end{aligned}
$$

The interaction of emulsifiers in the asphalt binder is shown in Figure 5. The results show that the anionic emulsifier has larger energy with either asphalt binder or water than the cationic emulsifier. The interaction between the asphalt binder and the anionic emulsifier is 3.9\% larger than that of the asphalt binder and the cationic emulsifier; while the interaction between water and anionic emulsifier is $39.7 \%$ larger than the cationic emulsifier. Based on some research, the larger the energy is, the less the stability is [31]. So, the cationic emulsifier is more stable with asphalt binder and water, confirming the conclusion mentioned above: the cationic emulsified asphalt binder is more stable than the anionic emulsified asphalt binder.

In addition, these interactions have relationship with breaking; therefore, it is inferred that the two emulsifiers on the interaction with water are significantly different; the stability between anionic emulsifier and water is poorer than the cationic emulsifier obviously, so it means that the anionic emulsifier would lose water easier during breaking, resulting in a larger viscosity shortly, which cause the mixable time too short, and workability is poor. This conclusion is consistent with the workability results.

3.5. Properties of Emulsified Asphalt Evaporation Residue. To investigate the emulsifier on properties of asphalt binder quantitatively, the emulsifier in $0.6 \%, 1.7 \%$, and $3.0 \%$ contents was added into the asphalt binder model in this section. For convenience, ID for different models was created: A0.6, A1.7, and A3.0 mean the emulsified asphalt evaporation residue with anionic emulsifier in dosage $0.6 \%$, $1.7 \%$, and 3.0\%, respectively. Similarly, C0.6, C1.7, and C3.0

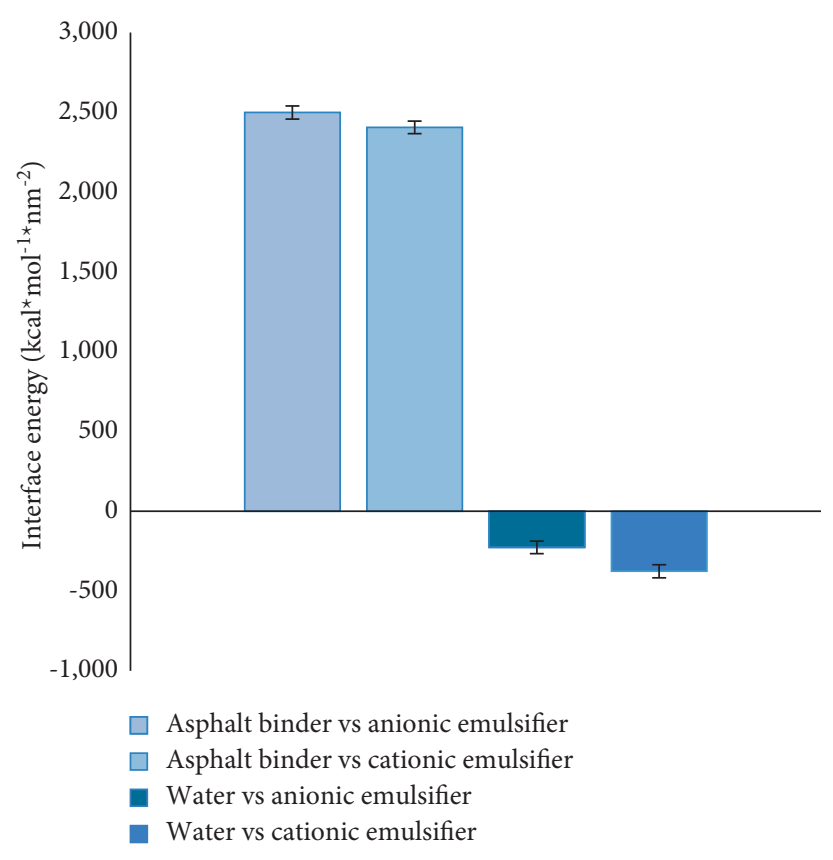

FIgURE 5: The interface energy results of the emulsifier.

mean the emulsified asphalt evaporation residue with the cationic emulsifier in dosage $0.6 \%, 1.7 \%$, and $3.0 \%$, respectively.

3.5.1. Density. For these three kinds of samples, the density of emulsified asphalt evaporation residue is simulated and calculated in this section. The specific results are shown in Figures 6(a) and 6(b).

Figure 6(a) shows the overall distribution of the density values of three samples: asphalt binder, A3.0, and C3.0 in the stable state; the ordering of these density values can be clearly seen; from large to small, it is A3.0, asphalt binder, and C3.0. Figure 6(b) shows the calculated average density value in the stable state of all samples. It is seen that the density of anionic emulsified asphalt evaporation residue decreases with the anionic emulsifier contents, while the 


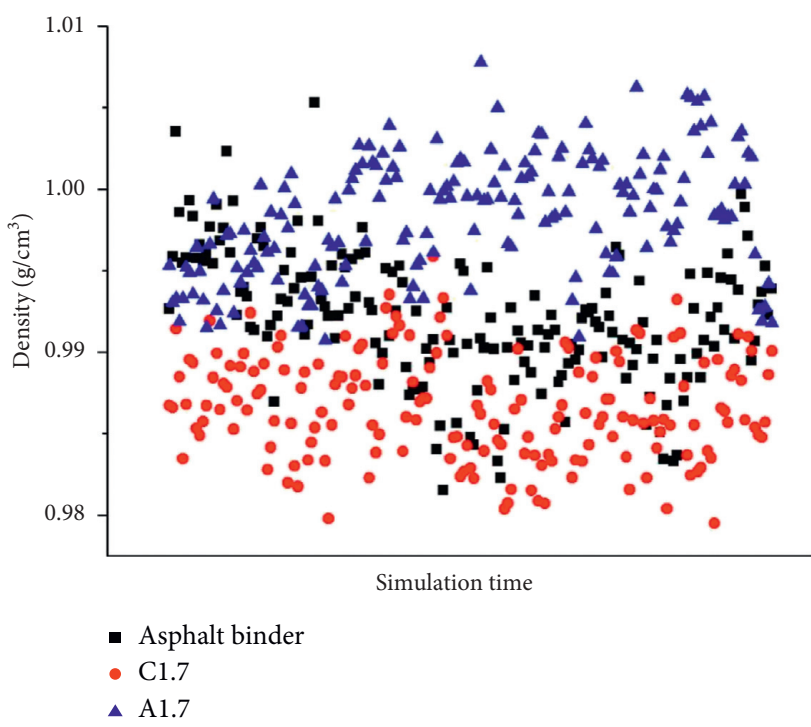

(a)

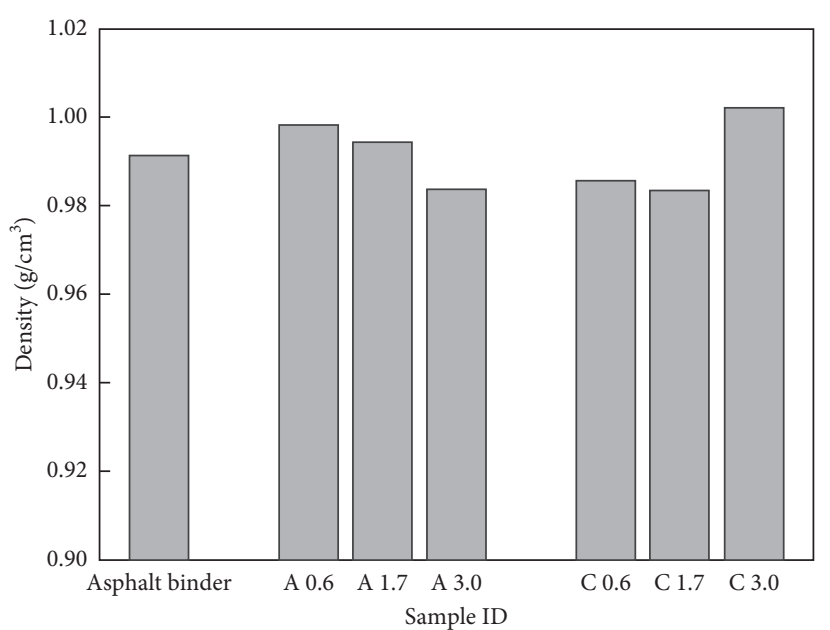

(b)

FIGURE 6: (a) The simulated density values of three kinds of samples; (b) the average density results.

trend between cationic emulsified asphalt evaporation residue and cationic emulsifier is not obvious, but the density of C3.0 is obviously larger than C0.6 and C1.7. In addition, the density of A0.6, A1.7, and C3.0 is greater than that of the asphalt binder based on the previous research [32]; there is a certain positive correlation between density and compressive strength of the asphalt binder; hence, the different types of emulsifiers should add into the asphalt binder in different contents. This point of view will be investigated more in depth in the subsequent section.

However, the compressive strength of emulsified asphalt mixture is generally worse comparing with the hot asphalt mixture due to its large void ratio. Therefore, the compressive strength of the emulsified asphalt mixture can be improved if its mixing process would be optimized.

3.5.2. Mechanical Properties. The mechanical properties of the asphalt binder have an important influence on road performance. So, the mechanical properties about two kinds of emulsified asphalt evaporation residue should be analyzed. Based on some previous research $[15,33]$, there is an obvious correlation between cohesive energy density (CED) and mechanical properties. The CED results are simulated and shown in Figure 7.

It is seen that both the anionic and cationic emulsified asphalt evaporation residue have a larger CED value comparing with the asphalt binder, indicating the anionic and cationic emulsified asphalt evaporation residue have better mechanical properties. There is an interesting pheromone; the density of emulsified asphalt evaporation residue A3, C0.6, and C1.7 is smaller, while their cohesive energy density is larger than the asphalt binder, concluding that the emulsifier plays a certain role in improving the mechanical properties of the asphalt binder.

However, as mentioned above, the mechanical properties of emulsified asphalt mixture are generally worse

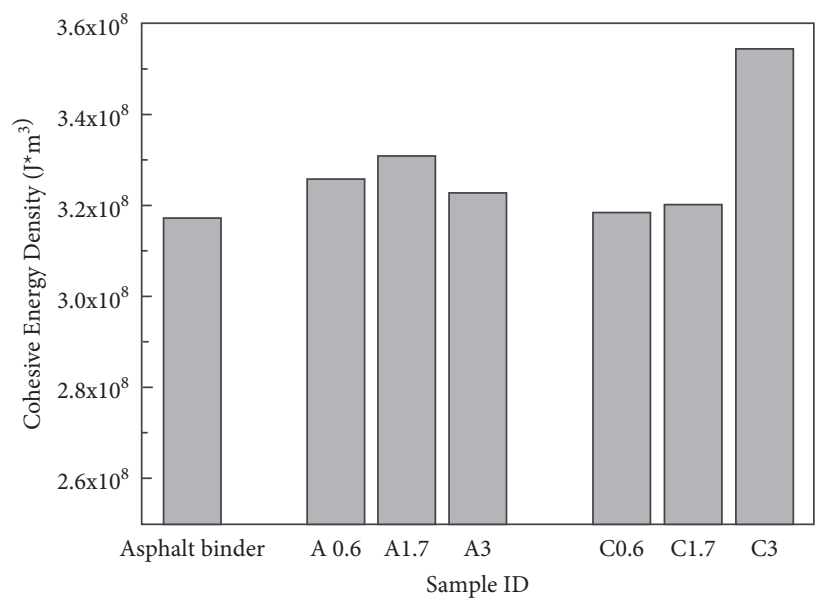

FIgURE 7: The CED results of different samples.

comparing with the hot asphalt mixture due to its large void ratio. So, it is theoretically inferred that the mechanical properties of the emulsified asphalt mixture would be better if its mixing process would be optimized to control the void ratio.

3.5.3. Adhesion Behavior. Some previous research has proven that the adhesion capability of the anionic emulsified asphalt binder is relatively poor due to its anion, which creates a repulsive force with the charge on the aggregate surface [34]. So, the adhesion behavior is investigated in this section.

The adhesion is a complex behavior, which contains micro- and macroscale behavior. However, a preliminary research of adhesion behavior is carried out on the micro; therefore, physical adhesion and roughness of the aggregate is ignored macroscopically. 
In order to research the adhesion behavior of the various kinds of bituminous binders, interface systems of silica and bituminous binders are established by putting a $30 \mathrm{~A}$ vacuum pad in them [27]. This interface model of aggregate and emulsified asphalt is almost the same with the interface model of aggregate and asphalt binder [33]. Based on the previous calculation method, their interface energy for adhesion results is shown in Figure 8.

The simulation result shows that the adhesion of each anionic bituminous binder is worse compared with the asphalt binder; meanwhile, the emulsified bituminous binder C0.6 has better adhesion, while C1.7 and C3.0 have worse adhesion than the bituminous binder. The adhesion properties of emulsified asphalt binders decrease with increasing emulsifier content. In general, cationic asphalt binders have good adhesion due to their positive charge [34], but as the cationic emulsifier content increases, their adhesion gradually decreases. This is mainly due to the limitations of the test method, i.e., the use of a macroscopic device to test the adhesion between the aggregate and the bituminous binder. The roughness of aggregate and macroscopic physical adhesion affects the results of the microadhesion properties. In this study, only the adhesion behavior at the microscopic scale was investigated.

3.6. Relationship between Emulsifier and Properties of Emulsified Asphalt Evaporation Residue. According to the results of properties of emulsified asphalt evaporation residue mentioned in Section 3.5, the different aging states about the same kind of the asphalt binder are analyzed; then, the effects of emulsifier type and content on the properties of emulsified asphalt evaporation residue are studied by variance (ANOVA) in SPSS. The analysis of ANOVA is shown in Table 1.

It is seen that the significance of the emulsifier type and content on density and CED are larger than 0.05 , indicating that the emulsifier type and content have little influence on the density and CED of the residue; while the significance of the emulsifier type and content on interaction energy is smaller than 0.05, meaning that the emulsifier type and content have an obvious impact on the adhesion behavior of the residue. According to this finding, the type and content of the emulsifier have a significant influence on the storage stability, workability, etc., of the emulsified asphalt binder, although they have limited effect on the density and CED of the residue, so it is favorable for emulsified asphalt that the emulsifier only works on emulsifying the asphalt binder into water and has no significant impact on the properties of residue. However, according to the analysis of ANOVA for interaction energy, it is suggested that the adhesion property should be considered in the production process of the emulsified asphalt binder.

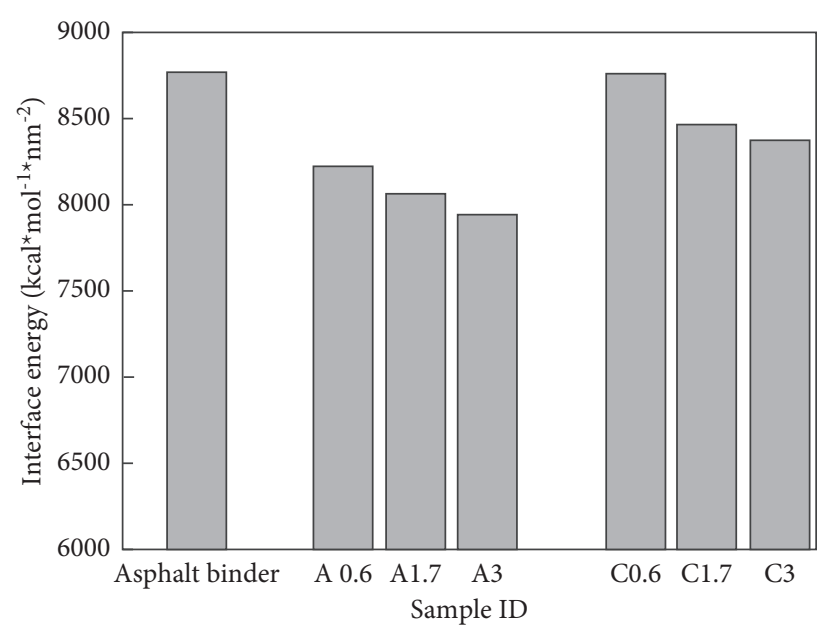

Figure 8: The interface energy results of three kinds of samples.

Table 1: ANOVA of density, CED, and interaction energy.

\begin{tabular}{lccc}
\hline \multirow{2}{*}{ Source } & \multicolumn{3}{c}{ Significance of variable } \\
& Density & CED & Interaction energy \\
\hline Emulsifier & 0.883 & 0.771 & 0.008 \\
Content & 0.948 & 0.649 & 0.040 \\
\hline
\end{tabular}

\section{Conclusion and Outlook}

A typical cationic emulsifier (dodecyl benzene sulfonate) and a typical anionic emulsifier (dodecyl primary amine) are studied from a microperspective in this study. Six models for two emulsifiers, two emulsified asphalt binders, and emulsified asphalt evaporation residue with different contents of the emulsifier are designed to research the influence of emulsifiers on the stability and workability of emulsified asphalt binder, and the properties of emulsified asphalt evaporation residue are also explored. Some conclusions are as follows:

(i) According to the microproperties of the emulsifier, it is found that the workability of cationic emulsified asphalt mixture is better, and the stability of the cationic emulsified asphalt binder is better.

(ii) The technical performance of the emulsified asphalt binder indicates that the cationic emulsified asphalt binder has better workability and road construction quality.

(iii) Based on the interaction between the emulsifier and asphalt binder/water, it is known that the stability of cationic emulsified asphalt is better than that of the anionic emulsified asphalt binder; on the contrary, the anionic emulsifier would lose water easier in the breaking, resulting in a larger viscosity shortly, 
which causes the mixable time to be too short, and workability is poor.

(iv) The properties of two kinds of emulsified asphalt evaporation residue show that the density of anionic emulsified asphalt evaporation residue is larger, while the mechanical properties of cationic emulsified asphalt evaporation residue are larger, indicating that the cationic emulsifier has some effect to improve the mechanical property of the asphalt binder theoretically.

Finally, according to the simulation analysis, some properties of the emulsified asphalt binder are better than those of the asphalt binder because the simulation is an ideal method to investigate these bituminous materials; if the construction process of emulsified asphalt mixture would be ideal, the porosity would be in the desired range, and the performance of the emulsified asphalt mixture would be better. So, the optimization of the construction process of the emulsified asphalt mixture will be the next focus in the future.

\section{Data Availability}

The data used to support the findings of this study are available from the corresponding author upon request.

\section{Conflicts of Interest}

The authors declare that there are no known conflicts of interest associated with this publication.

\section{Acknowledgments}

This study was supported by the National Natural Science Foundation of China, under Grant nos. 52078048 and 52008029. The researchers gratefully acknowledge financial support of the foundation, and they are in charge of the authenticity of the test data.

\section{References}

[1] Y. Tan, J. Ouyang, J. Lv, and Y. Li, "Effect of emulsifier on cement hydration in cement asphalt mortar," Construction and Building Materials, vol. 47, pp. 159-164, 2013.

[2] Z. Wang, Q. Wang, T. Ai, J. Conbuildmat, C. E. A. Mixture, and C. Ages, "Comparative study on effects of binders and curing ages on properties of cement emulsified asphalt mixture using gray correlation entropy analysis," Construction and Building Materials, vol. 54, pp. 615-622, 2014.

[3] D. D. Li and M. L. Greenfield, "Chemical compositions of improved model asphalt systems for molecular simulations," Fuel, vol. 115, pp. 347-356, 2014.

[4] L. Zhang and M. L. Greenfield, "Relaxation time, diffusion, and viscosity analysis of model asphalt systems using molecular simulation," The Journal of Chemical Physics, vol. 127, no. 19, Article ID 194502, 2007.

[5] L. Zhang and M. L. Greenfield, "Effects of polymer modification on properties and microstructure of model asphalt systems," Energy \& Fuels, vol. 22, no. 5, pp. 3363-3375, 2008.

[6] M. Guo, M. Liang, A. Anand, A. Amit, and D. Luo, "Characterisation of rejuvenation of various modified asphalt binders based on simplified chromatographic techniques," International Journal of Pavement Engineering, vol. 2, pp. 111, 2021.

[7] M. Guo, X. Liu, Y. Jiao, Y. Tan, and D. Luo, "Rheological characterization of reversibility between aging and rejuvenation of common modified asphalt binders," Construction and Building Materials, vol. 301, Article ID 124077, 2021.

[8] M. Guo, H. Liu, Y. Jiao et al., "Effect of WMA-RAP technology on pavement performance of asphalt mixture: a state-of-theart review," Journal of Cleaner Production, vol. 266, Article ID 121704, 2020.

[9] H. T. Osborn and C. C. Akoh, "Effect of emulsifier type, droplet size, and oil concentration on lipid oxidation in structured lipid-based oil-in-water emulsions," Food Chemistry, vol. 84, no. 3, pp. 451-456, 2004.

[10] P. D. Ribotta, G. T. Pérez, A. E. León, and M. C. Añón, "Effect of emulsifier and guar gum on micro structural, rheological and baking performance of frozen bread dough," Food Hydrocolloids, vol. 18, no. 2, pp. 305-313, 2004.

[11] W. G. Waggoner and J. H. Fincher, "Influence of hlb values of surfactants on ephedrine release from emulsified liquid systems," Journal of Pharmaceutical Sciences, vol. 60, no. 12, pp. 1830-1835, 2010.

[12] L. Zhang and M. L. Greenfield, "Analyzing properties of model asphalts using molecular simulation," Energy \& Fuels, vol. 21, no. 3, pp. 1712-1716, 2007.

[13] L. Zhang and M. L. Greenfield, "Rotational relaxation times of individual compounds within simulations of molecular asphalt models," The Journal of Chemical Physics, vol. 132, no. $18,2010$.

[14] Y. Hou, L. Wang, D. Wang, M. Guo, P. Liu, and J. Yu, "Characterization of bitumen micro-mechanical behaviors using AFM, phase dynamics theory and MD simulation," Materials, vol. 10, no. 2, 2017.

[15] X. Qu, D. Wang, Y. Hou, Q. Liu, M. Oeser, and L. Wang, "Investigation on self-healing behavior of asphalt binder using a six-fraction molecular model," Journal of Materials in Civil Engineering, vol. 31, no. 5, Article ID 04019046, 2019.

[16] X. Qu, Q. Liu, M. Guo, D. Wang, and M. Oeser, "Study on the effect of aging on physical properties of asphalt binder from a microscale perspective," Construction and Building Materials, vol. 187, pp. 718-729, 2018.

[17] I. A. Wiehe and K. S. Liang, "Asphaltenes, resins, and other petroleum macromolecules," Fluid Phase Equilibria, vol. 117, no. 1-2, pp. 201-210, 1996.

[18] L. W. Corbett, "Composition of asphalt based on generic fractionation, using solvent deasphaltening, elution-adsorption chromatography, and densimetric characterization," Analytical Chemistry, vol. 41, no. 4, pp. 576-579, 1969.

[19] G. Šebor, J. Blažek, and M. F. Nemer, "Optimization of the preparative separation of petroleum maltenes by liquid adsorption chromatography," Journal of Chromatography A, vol. 847, no. 1-2, pp. 323-330, 1999.

[20] X. Quan, L. Kong, H. Wang, Y. Zhang, W. Luo, and B. Yang, "Molecular dynamics and experimental study on the influence of hydrophilic group on the adsorption of dodecyl anionic emulsifier on $\mathrm{SiO} 2$ surface," Acta Materiae Compositae Sinica, pp. 1-15, 2021.

[21] L. Shi, L. Cao, M. Wang, Y. Chen, and T. Ji, "Synthesis of octadecyl-bis(2-hydroxypropyl)-sodium acetate-based ammonium chloride asphalt emulsifier," Journal of Pingdingshan University, vol. 035, no. 2, pp. 30-35, 2020.

[22] L. Shi, Z. Yang, R. Zhao, Z. Ren, T. Wang, and Y. Chen, "Synthesis and performance of quaternary ammonium 
asphalt emulsifier based on octadecylamine," Journal of Pingdingshan University, vol. 34, no. 2, pp. 50-57, 2019.

[23] D. W. V. Krevelen and K. T. Nijenhuis, Properties of Polymers: Their Correlation with Chemical Structure; Their Numerical Estimation and Prediction from Additive Group Contributions, Elsevier, Amsterdam, Netherland, 2009.

[24] H. Wang, C. Wang, and Z. Wang, "The Influence of Emulsifier System on the storage stability of emulsified asphalt," $\mathrm{Pe}$ troleum asphalt, vol. 22, no. 4, pp. 10-13, 2008.

[25] B. Derjaguin and L. Landau, "Theory of the stability of strongly charged lyophobic sols and of the adhesion of strongly charged particles in solutions of electrolytes," Progress in Surface Science, vol. 43, pp. 30-59, 1941.

[26] E. J. W. Verwey, "Theory of the stability of lyophobic colloids," The Journal of Physical and Colloid Chemistry, vol. 51, no. 3, 636 pages, 1947.

[27] D. Tian, Q. Yuan, R. Zhu, C. Wang, and D. Deng, "Effect of water on static mechanical properties of cement emulsified asphalt mortar," Journal of the Chinese Ceramic Society, vol. 40, no. 11, pp. 1544-1552, 2012.

[28] D. Wang, P. Hao, N. Liu, H. Zhang, and Z. Li, "Workability Indicator For Emulsified Asphalt Recycled Mixture And Influence Factors," Journal of Beijing University Technology, 2016.

[29] M. F. Kuo, C. T. Lu, J. C. Du, and Y. K. Chen, "Workability of fresh cement-asphalt mastic," Applied Mechanics and Materials, vol. 368-370, pp. 1027-1030, 2013.

[30] J. Ouyang, Y. Tan, Y. Li, and J. Zhao, "Demulsification process of asphalt emulsion in fresh cement-asphalt emulsion paste," Materials and Structures, vol. 48, no. 12, pp. 3875-3883, 2015.

[31] G. Xu and H. Wang, "Study of cohesion and adhesion properties of asphalt concrete with molecular dynamics simulation," Computational Materials Science, vol. 112, pp. 161-169, 2016.

[32] X. Qu, D. Wang, Y. Hou, M. Oeser, and L. Wang, "Influence of paraffin on the microproperties of asphalt binder using MD simulation," Journal of Materials in Civil Engineering, vol. 30, no. 8, Article ID 04018191, 2018.

[33] X. Qu, Q. Liu, C. Wang, D. Wang, and M. Oeser, "Effect of Co-production of renewable biomaterials on the performance of asphalt binder in macro and micro perspectives," Materials, vol. 11, no. 2, 2018.

[34] S. Han and D. Zhang, "Study on factors affecting the adhesion of mineral materials and emulsified asphalt," Petroleum asphalt, vol. 9, no. 1, pp. 23-25, 1995. 